\title{
AVALIAÇÃO DE GENÓTIPOS E VARIEDADES DE ACEROLA PARA CONSUMO IN NATURA E PARA ELABORAÇÃO DE DOCES
}

\author{
ROSSANA CATIE BUENO DE GODOY* \\ EDNEIDE LUCIANASANTIAGO MATOS** \\ TATIANE DA SILVAAMORIM ${ }^{\star \star \star \star}$ \\ MANOELALVES DE SOUSA NETO**** \\ ROGÉRIO RITZINGER ${ }^{\star \star \star \star \star ~}$ \\ NINA WASZCZYNSKYJ******
}

\begin{abstract}
Os frutos de acerola diferem quanto à sua composição devido à variabilidade genética, podendo ser classificados em doces, semi-doces e ácidos. O objetivo desse estudo foi a caracterização físico-química, química e sensorial de frutos de três genótipos de acerola in natura e processados na forma de doces. Os frutos avaliados foram menos ácidos do que os relatados pela literatura, apresentando valores intermediários de vitamina $\mathrm{C}$. A variedade Rubra alcançou maior aceitação para consumo in natura por ser menos ácida e por apresentar teores mais elevados de sólidos solúveis totais. Os doces diferiram significativamente quanto aos parâmetros analisados, conforme o genótipo utilizado na sua confecção, sendo que os frutos do genótipo CMF-017 proporcionaram qualidade superior ao produto.
\end{abstract}

PALAVRAS-CHAVE: ACEROLA; Malpighia emarginata; DOCES; VITAMINA C.

* Engenheira Agrônoma, Doutoranda em Tecnologia de Alimentos, Pesquisadora da Embrapa Florestas, Colombo, PR (e-mail: catie.godoy@gmail.com).

** Engenheira Agrônoma, Mestranda em Recursos Genéticos, Universidade Federal do Recôncavo Baiano, Cruz das Almas, BA (e-mail:edneidematos@yahoo.com.br).

*** Engenheira Agrônoma, Assistente da Embrapa Mandioca e Fruticultura Tropical, Cruz das Almas, BA (e-mail: tatiane@cnpmf.embrapa.br).

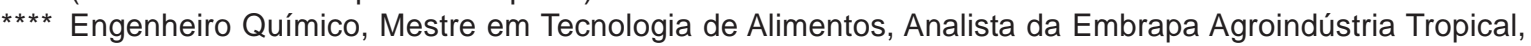
Fortaleza, CE (e-mail: manoel@cnpat.embrapa.br).

*****Engenheiro Agrônomo, Doutor em Melhoramento de Plantas, Pesquisador da Embrapa Mandioca e Fruticultura Tropical, Cruz das Almas, BA (e-mail: rogerio@cnpmf.embrapa.br).

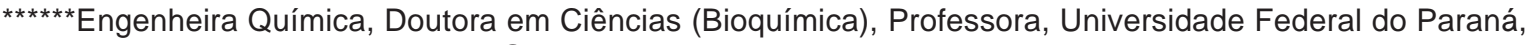
Curitiba, PR (e-mail: ninawas@ufpr.br). 


\section{INTRODUÇÃO}

A aceroleira pertence à família Malpighiaceae, gênero Malpighia, cuja família conta com cerca de 63 gêneros e 850 espécies. Apesar da sua classificação botânica ser bastante controversa, a acerola como é conhecida corresponde à espécie Malpighia emarginata Sessé \& Moc. ex D.C. (OLIVEIRA et al., 2003).

O abastecimento de acerola no mercado pode ser considerado como difícil pela fragilidade dos frutos, que são bastante perecíveis. Desta forma, o processamento dos frutos é imprescindível para a manutenção da cadeia produtiva dessa espécie.

O aproveitamento da acerola inclui, dentre outros produtos, a elaboração de polpas, sucos, compotas, doces em massa, geléias, licores e refrigerantes (MANICA, 2003). No entanto, devido à variabilidade genética, os frutos provenientes de diferentes genótipos apresentam diferenças quanto a tamanho, coloração da casca e da polpa, composição físico-química, suculência, textura, aroma e sabor (RITZINGER, SOARES FILHO e OLIVEIRA, 2003).

Os frutos são drupas de forma bastante variável. Há frutos arredondados, ovalados ou mesmo cônicos. Sua cor atribuída ao pigmento do grupo das antocianinas pode ser amarela, vermelha ou roxa quando maduras (FRANÇA, 1999).

As variedades de acerola podem ser classificadas em doces, semi-doces e ácidas, sendo que sua diferenciação ocorre em função dos teores de sólidos solúveis totais e acidez total titulável nos frutos maduros (RITZINGER, SOARES FILHO e OLIVEIRA, 2003). As variedades doces, preferidas para o consumo in natura, caracterizam-se por apresentar valores de sólidos solúveis totais elevados (iguais ou superiores a $11^{\circ}$ Brix), e valores de acidez total titulável iguais ou inferiores a $1 \%$ de ácido málico (LASKOWSKI e BAUTISTA, 1998). As variedades ácidas, mais utilizadas para a industrialização, apresentam sabor pouco agradável devido ao elevado teor de acidez (superior a 1\% de ácido málico). Já as variedades semi-doces contém teores intermediários de sólidos solúveis totais e acidez total titulável, o que lhes confere aptidão tanto para a indústria quanto para o consumo ao natural.

O interesse pelo desenvolvimento de variedades de acerola tem sido motivado principalmente pelo alto teor de vitamina $C$ da fruta, considerada como uma das mais ricas em vitamina $C$ ao lado de espécies como o camu-camu e a cabeludinha (MANICA et al., 2007).

GOMES et al. (2000) avaliaram as variações físico-químicas de suco de acerola armazenado proveniente de cinco diferentes genótipos. Verificaram ao final de 10 meses, que alguns genótipos eram superiores devido maior estabilidade de vitamina $C$ em relação aos demais.

Dentre os cerca de 150 acessos do Banco Ativo de Germoplasma de Acerola da Embrapa Mandioca e Fruticultura Tropical, provenientes de coletas efetuadas nas regiões Nordeste, Sudeste e Norte foram preliminarmente selecionados três genótipos com características agronômicas adequadas para consumo in natura ou para industrialização. Este trabalho objetivou a caracterização físico-química, química e sensorial dos frutos dessas variedades de acerola nas condições de consumo in natura e para o processamento de doce em massa.

\section{MATERIAL E MÉTODOS}

Os frutos de acerola foram colhidos no estágio maduros (coloração da casca vermelha) de plantas do genótipo CMF 017 e das variedades Rubra e Cabocla no Banco Ativo de Germoplasma de Acerola da Embrapa Mandioca e Fruticultura Tropical, localizado em Cruz das Almas (BA). A elaboração do doce em massa de acerola ocorreu no Laboratório de Ciência e Tecnologia de Alimentos da Embrapa Mandioca e Fruticultura Tropical. Seguiu-se a metodologia descrita por ALMEIDA, SCHMIDT e GASPARINO FILHO (1999) que inclui as etapas de recepção das frutas, seleção, lavagem, branqueamento, despolpamento, homogeneização, formulação ( $50 \%$ açúcar e $50 \%$ de polpa), adição de pectina, concentração ( $73^{\circ}$ Brix) e envasamento. 
As avaliações físico-químicas consistiram na determinação do $\mathrm{pH}$, mediante leitura em pHmetro digital, e dos sólidos solúveis totais (SST), mediante leitura em refratômetro, método 932.14C (AOAC, 1990). As avaliações químicas de acidez total titulável (ATT) e vitamina C foram obtidas por titulação com $\mathrm{NaOH}, 0,1 \mathrm{~N}$, método 942.15 (AOAC, 1990) e por titulometria com 2,6 Diclorofenol indolfenol, método de Tillmans (LEES, 1975), respectivamente. A vitamina C foi expressa em mg ác.ascórbico.100 $\mathrm{g}^{-1}$.

Mediu-se a cor das amostras em colorímetro MINOLTA CR300 (MINOLTA, 1991), sistema CIE $L^{*} a^{*} b^{*}\left(L^{*}=\right.$ luminosidade; $a^{*}=$ intensidade de vermelho; $b^{*}=$ intensidade de amarelo). A calibração do aparelho foi realizada por meio de placa de cerâmica branca, utilizando-se o iluminante D65. As medidas foram tomadas de forma direta e a média das três determinações considerada como resposta para o parâmetro cor.

Avaliou-se a textura em texturômetro TAXT2i (STABLE MICRO SYSTEM, 1997) com sonda cilíndrica de aço inoxidável ( $\varnothing 6 \mathrm{~mm}$ ). Efetuou-se a compressão na velocidade de $1 \mathrm{~mm} / \mathrm{s}$, com distância de penetração de $20 \mathrm{~mm}$. Em cada amostra, foram avaliadas a dureza (força de resistência máxima oferecida pela amostra antes da ruptura da superfície do gel, em gramas) e adesividade (energia para remoção da sonda, correspondente à área negativa sob o gráfico da textura, em g.mm). As análises foram feitas em triplicata.

Nas análises sensoriais, os frutos para consumo in natura foram servidos inteiros em pratos descartáveis devidamente codificados. As amostras de doces foram dispostas em cubos de $6 \times 3 \times 2 \mathrm{~cm}$, aproximadamente, seguindo a mesma metodologia de apresentação. As análises foram realizadas em cabines com temperatura controlada. Foram recrutados 50 julgadores não-treinados entre funcionários, estudantes e visitantes da Embrapa Mandioca e Fruticultura Tropical. Utilizou-se escala verbal e numérica de 7 pontos, sendo: 1 - desgostei muito; 2 - desgostei regularmente; 3 desgostei ligeiramente; 4 - não gostei nem desgostei; 5 - gostei ligeiramente; 6 - gostei regularmente e 7 - gostei muito (FERREIRA et al., 2000). Os atributos avaliados para os frutos frescos foram: aparência, cor, aroma, sabor e suculência. Para os doces, os atributos foram: aparência, cor, aroma, ponto de corte e sabor.

Utilizou-se delineamento inteiramente casualizado, com três tratamentos e cinco repetições para as avaliações químicas e físico-químicas. Os resultados foram submetidos à análise de variância e as diferenças entre médias comparadas pelo teste de Tukey a $5 \%$ de probabilidade. Para as avaliações sensoriais utilizou-se o delineamento em blocos casualizados em que cada julgador constituiu uma repetição, comparando-se as médias pelo teste de Tukey a 5\% de probabilidade (GOMES, 2000).

\section{RESULTADOS E DISCUSSÃO}

\subsection{FRUTOS IN NATURA}

Os três genótipos de aceroleira diferiram significativamente entre si nas avaliações físicoquímicas e químicas dos frutos frescos. A média dos valores de $\mathrm{pH}$ foi de 3,45 (Tabela 1), sendo que a variedade Rubra apresentou valores significativamente maiores $(\mathrm{pH}=3,60)$ e menores teores de acidez $(0,830 \%$ de ácido málico). SEMENSATO (1997) obteve valores médios de $\mathrm{pH}(2,38)$ para frutos de acerola cultivados em Anápolis (GO) e FRANÇA (1999) valores de 3,31 em genótipos coletados no Estado de Pernambuco. MUSSER et al. (2004), avaliando 12 genótipos de acerola do Banco Ativo de Germoplasma da Universidade Federal de Pernambuco obtiveram a média de pH de 3,20.

A acidez total titulável (ATT) média dos materiais avaliados foi de 1,09\% de ácido málico, sendo que a variedade Rubra apresentou o menor valor. CAVALCANTE et al. (2004) encontraram valores médios de acidez (2,49\%) para dois clones de acerola provenientes de Jaboticabal, e portanto mais ácidas que as acerolas desse estudo.

A média de sólidos solúveis totais (SST) foi de $8,24^{\circ} \mathrm{Brix}$, sendo maior na variedade Rubra 
(8,84Bix). O genótipo CMF-017 e a variedade Cabocla apresentaram menores teores de sólidos solúveis totais, não diferindo estatisticamente entre si. Os valores obtidos foram superiores a $6,21^{\circ} \mathrm{Brix}$, encontrado por FRANÇA (1999), a 7, $6^{\circ}$ Brix verificado por MUSSER et al. (2004) e 6,57 ${ }^{\circ}$ Brix constatado por CHAVES et al. (2004).

A relação SST/ATT está ligada ao sabor dos frutos, sendo mais elevada em frutos doces. A variedade Rubra destacou-se dentre os materiais estudados, apresentando relação SST/ATT de 10,71 .

O teor médio de vitamina C (1052,03 mg/100 g polpa) enquadrou-se na recomendação do programa de melhoramento (superior a $1000 \mathrm{mg} / 100 \mathrm{~g}$ polpa e mínimo de $800 \mathrm{mg} / 100 \mathrm{~g}$ polpa), estabelecida pela legislação para polpas de acerola (BRASIL, 2000). No entanto, valores superiores de vitamina $C$ foram encontrados por GOMES et al. (2000), MUSSER et al. (2004) e CARPENTIERIPÍPOLO et al. (2002), cujas médias alcançaram 1632,6 mg/100 g polpa, $1434 \mathrm{mg} / 100 \mathrm{~g}$ polpa e $1268 \mathrm{mg} / 100 \mathrm{~g}$ polpa, respectivamente. É importante ressaltar que esses autores avaliaram genótipos diferentes dos abordados no presente trabalho, mais adequados para o mercado de processamento por apresentarem maiores teores de ATT e vitamina C.

\section{TABELA 1 - AVALIAÇÕES FÍSICO-QUÍMICAS E QUÍMICAS DE FRUTOS PROVENIENTES DE DIFERENTES GENÓTIPOS DE ACEROLEIRA}

\begin{tabular}{lccccc}
\hline Genótipos & $\mathrm{pH}$ & $\begin{array}{c}\text { SST } \\
\left({ }^{\circ} \mathrm{Brix}\right)\end{array}$ & $\begin{array}{c}\text { ATT } \\
(\%)\end{array}$ & SST/ATT & $\begin{array}{c}\text { Vitamina C } \\
\left.\text { (mg.100 } \mathrm{g}^{-1} \text { polpa }\right)\end{array}$ \\
\hline CMF-017 & $3,29 \mathrm{c}$ & $7,88 \mathrm{~b}$ & $1,35 \mathrm{a}$ & $5,84 \mathrm{c}$ & $1191,90 \mathrm{a}$ \\
RUBRA & $3,60 \mathrm{a}$ & $8,84 \mathrm{a}$ & $0,83 \mathrm{c}$ & $10,71 \mathrm{a}$ & $911,96 \mathrm{~b}$ \\
CABOCLA & $3,46 \mathrm{~b}$ & $8,02 \mathrm{~b}$ & $1,10 \mathrm{~b}$ & $7,26 \mathrm{~b}$ & $1052,23 \mathrm{ab}$ \\
\hline Média Geral & 3,45 & 8,24 & 1,09 & 7,94 & 1052,03 \\
CV (\%) & 0,92 & 5,11 & 8,82 & 8,14 & 13,96 \\
\hline
\end{tabular}

SST = sólidos solúveis totais; ATT = acidez total titulável; CV = coeficiente de variação.

Médias seguidas pela mesma letra nas colunas não diferem estatisticamente entre si pelo teste de Tukey a $5 \%$ de probabilidade $(\mathrm{P} \leq 0,05)$.

$\mathrm{Na}$ avaliação sensorial dos frutos não houve diferença significativa entre as amostras para os atributos aparência, cor, aroma e suculência. No entanto, os frutos da variedade Cabocla atingiram maiores médias para a aparência e a cor. Para aroma destacaram-se os frutos do genótipo CMF-017 e para suculência os frutos da variedade Rubra (Tabela 2).

Com relação ao atributo sabor, as diferenças entre os frutos foram significativas. Os frutos da variedade Rubra, os mais apreciados no teste sensorial, obtiveram média 6,00 (gostei regularmente). Nas avaliações físico-químicas e químicas tais frutos mostraram menores teores de acidez e maiores teores de sólidos solúveis totais, proporcionando balanço adequado entre sabor doce e ácido, confirmado pela alta relação SST/ATT apresentada.

BRUNINI et al. (2004) avaliaram as características físico-químicas de acerolas oriundas de oito regiões do Estado de São Paulo, relacionando-as com o sabor dos frutos. Quando a relação SST/ ATT dos materiais avaliados situou-se acima de 8,00, os julgadores mostraram tendência para classificar os frutos como doces.

Considerando-se a somatória de todos os atributos sensoriais avaliados, a variedade Rubra foi a mais apreciada para o consumo ao natural. 
TABELA 2 - AVALIAÇÃO SENSORIAL DE FRUTOS PROVENIENTES DE DIFERENTES

GENÓTIPOS DE ACEROLEIRA

\begin{tabular}{lccccc}
\hline Genótipos & Aparência & Cor & Aroma & Sabor & Suculência \\
& & & & & \\
\hline CMF-017 & $5,80 \mathrm{a}$ & $5,50 \mathrm{a}$ & $5,83 \mathrm{a}$ & $4,40 \mathrm{~b}$ & $5,26 \mathrm{a}$ \\
RUBRA & $5,13 \mathrm{a}$ & $5,66 \mathrm{a}$ & $5,60 \mathrm{a}$ & $6,00 \mathrm{a}$ & $5,83 \mathrm{a}$ \\
CABOCLA & $5,90 \mathrm{a}$ & $5,90 \mathrm{a}$ & $5,26 \mathrm{a}$ & $4,86 \mathrm{~b}$ & $5,60 \mathrm{a}$ \\
\hline Média Geral & 5,61 & 5,68 & 5,56 & 5,08 & 5,56 \\
CV $(\%)$ & 25,70 & 24,92 & 23,21 & 30,58 & 23,53 \\
& & & & & \\
\hline
\end{tabular}

$\mathrm{CV}=$ coeficiente de variação.

Médias seguidas pela mesma letra nas colunas não diferem estatisticamente entre si pelo teste de Tukey a 5\% de probabilidade $(\mathrm{P} \leq 0,05)$.

\subsection{DOCE EM MASSA}

Com exceção do teor de vitamina C, os três genótipos de aceroleira diferiram significativamente entre si nas avaliações físico-químicas e químicas dos doces em massa. Os doces elaborados com frutos do genótipo CMF-017 e da variedade Rubra apresentaram o menor e o maior pH dentre as amostras avaliadas, respectivamente (Tabela 3). O doce com menor teor de sólidos solúveis totais foi elaborado com frutos do genótipo CMF-017 ( $75,40^{\circ}$ Brix), possivelmente devido ao menor teor de SST nos frutos. Os valores de acidez total titulável oscilaram de $0,85 \%$ a 1,13\% de ácido málico e não apresentaram correlação com o comportamento do $\mathrm{pH}$, sendo a acidez maior no doce elaborado a partir de frutos da variedade Cabocla.

TABELA 3 - AVALIAÇÕES FÍSICO-QUÍMICAS E QUÍMICAS DE DOCES EM MASSA ELABORADOS COM FRUTOS PROVENIENTES DE DIFERENTES GENÓTIPOS DE ACEROLEIRA

\begin{tabular}{lcccc}
\hline Genótipos & $\mathrm{pH}$ & $\begin{array}{c}\text { SST } \\
\left({ }^{\circ} \mathrm{Brix}\right)\end{array}$ & $\begin{array}{c}\text { ATT } \\
(\%)\end{array}$ & $\begin{array}{c}\text { Vitamina C } \\
\left(\mathrm{mg} .100 \mathrm{~g}^{-1} \text { polpa }\right)\end{array}$ \\
\hline CMF-017 & $3,25 \mathrm{c}$ & $75,40 \mathrm{~b}$ & $0,96 \mathrm{~b}$ & $558,86 \mathrm{a}$ \\
RUBRA & $3,59 \mathrm{a}$ & $79,80 \mathrm{a}$ & $0,85 \mathrm{c}$ & $581,20 \mathrm{a}$ \\
CABOCLA & $3,46 \mathrm{~b}$ & $79,75 \mathrm{a}$ & $1,13 \mathrm{a}$ & $558,91 \mathrm{a}$ \\
\hline Média Geral & 3,43 & 78,31 & 0,98 & 566,32 \\
CV $(\%)$ & 1,01 & 1,82 & 5,13 & 6,45 \\
& & & & \\
\hline
\end{tabular}

SST = sólidos solúveis totais; ATT = acidez total titulável; CV = coeficiente de variação.

Médias seguidas pela mesma letra nas colunas não diferem estatisticamente entre si pelo teste de Tukey a $5 \%$ de probabilidade $(\mathrm{P} \leq 0,05)$.

JALALI e SOUZA (1994) relataram que o suco de acerola, após tratamento térmico, manteve $495 \mathrm{mg}$ ác. ascórbico. $100 \mathrm{~g}^{-1}$. Outros trabalhos científicos têm comprovado a estabilidade da vitamina C em produtos processados de acerola. GOMES et al. (2000) avaliaram o suco de acerola após 10 meses de congelamento e obtiveram a média de $1724,25 \mathrm{mg}$ ác.ascórbico. $100 \mathrm{~g}^{-1}$ no produto. A perda num genótipo foi de 2,22\%, enquanto que em outro alcançou $26 \%$.

SEMENSATO (1997) observou, após 90 dias de armazenamento, que o doce em massa de acerola continha $762 \mathrm{mg}$ ác.ascórbico. $100 \mathrm{~g}^{-1}$, representando perda de $26,73 \%$ em relação ao fruto 
in natura. Neste mesmo estudo, o autor avaliou a estabilidade da vitamina $\mathrm{C}$ para a fruta congelada, doce em calda, doce cremoso, doce em massa, geléia, licor, néctar, polpa congelada e suco integral pasteurizado após 30 dias. Verificou que a maioria dos produtos reteve mais de $50 \%$ da vitamina $C$ contida nos frutos frescos.

Os parâmetros de textura avaliados nos doces em massa (Tabela 4) revelaram menor firmeza do gel para a amostra Cabocla (menor valor médio de dureza), diferindo significativamente das demais. Com relação à adesividade, as amostras não diferiram significativamente entre si. A amostra CMF017, no entanto, apresentou características de textura mais adequadas (maior firmeza do gel associada com adesividade não tão elevada), o que pode ser confirmado pelos resultados da análise sensorial com relação ao ponto de corte.

A análise de cor $L^{*} a^{*} b^{*}$ (Tabela 4) mostrou diferença significativa entre as amostras. A amostra Rubra apresentou baixa luminosidade $(24,24)$, indicando tratar-se de doce mais escuro que os elaborados com o genótipo CMF-017 e a variedade Cabocla. Baixos valores dos parâmetros $\mathrm{a}^{\star} \mathrm{e}^{\text {* }}$ * indicaram amostras com pouca coloração (cromaticidade) e predominância da cor amarela (valores de $\left.b^{\star}\right)$ sobre a cor vermelha $\left(a^{*}\right)$ em todos os doces analisados. A amostra Cabocla evidenciou a maior intensidade de amarelo, apesar de não diferir estatisticamente das demais. A amostra CMF-017 revelou a maior intensidade de vermelho, diferindo estatisticamente das demais. A predominância da cor vermelha no doce elaborado com o genótipo CMF-017 pode explicar a superioridade dessa amostra em relação às demais na avaliação da cor pelos julgadores.

\section{TABELA 4 - AVALIAÇÕES DE TEXTURA E COR DE DOCES EM MASSA ELABORADOS COM FRUTOS PROVENIENTES DE DIFERENTES GENÓTIPOS DE ACEROLEIRA}

\begin{tabular}{|c|c|c|c|c|c|}
\hline \multirow[t]{2}{*}{ Genótipos } & \multirow{2}{*}{$\begin{array}{l}\text { Força } \\
(\mathrm{g})\end{array}$} & \multirow{2}{*}{$\begin{array}{l}\text { Adesividade } \\
(\text { g. } \mathrm{mm})\end{array}$} & \multicolumn{3}{|c|}{ Cor } \\
\hline & & & $\left(L^{*}\right)$ & $\left(a^{*}\right)$ & $\left(b^{*}\right)$ \\
\hline CMF-017 & $158,75 a$ & $-668,98 a$ & $25,93 a$ & $3,11 \mathrm{a}$ & $4,81 \mathrm{a}$ \\
\hline RUBRA & $157,69 \mathrm{a}$ & $-776,50 a$ & $24,24 b$ & $1,67 \mathrm{~b}$ & $4,71 \mathrm{a}$ \\
\hline CABOCLA & $122,89 \mathrm{~b}$ & $-669,30 a$ & $26,87 \mathrm{a}$ & $1,91 b$ & $6,63 a$ \\
\hline Média Geral & 146,44 & $-704,93$ & 25,68 & 2,23 & 5,38 \\
\hline CV $(\%)$ & 11,82 & $-11,98$ & 3,29 & 23,41 & 30,67 \\
\hline
\end{tabular}

$\mathrm{CV}=$ coeficiente de variação

Médias seguidas pela mesma letra nas colunas não diferem estatisticamente entre si pelo teste de Tukey a $5 \%$ de probabilidade $(\mathrm{P} \leq 0,05)$.

Com relação à aparência dos doces em massa, a média geral alcançou 5,42 na escala de avaliação (Tabela 5). No entanto, houve diferença significativa entre os doces elaborados com o genótipo CMF-017 $(6,06)$ em relação aos elaborados com as variedades Cabocla e Rubra (médias de 5,16 e 5,04 , respectivamente).

A cor do produto foi a característica mais apreciada pelos julgadores (5,70). FRANÇA (1999), avaliando a cor do doce de acerola em massa obteve de 60,6 a 79,0\% de aceitação dos consumidores. A cor do doce produzido com o genótipo CMF-017 foi considerada superior na avaliação dos julgadores, embora não tenha diferido estatisticamente da variedade Cabocla. $O$ doce produzido com a variedade Rubra apresentou coloração menos atrativa.

Para o aroma não foi detectada diferença significativa entre os produtos avaliados, embora o doce com o genótipo CMF-017 tenha alcançado médias maiores. De maneira geral, o aroma mostrouse o atributo menos atrativo na opinião dos julgadores $(5,29)$. Isto ocorre pela grande perda dos compostos voláteis durante a etapa de concentração. 
O ponto de corte foi estabelecido como aquele que o produto não ofereçe resistência e não há adesividade ou pegajosidade. O doce elaborado com frutos do genótipo CMF-017 demonstrou ponto de corte significativamente superior ao dos doces elaborados com as variedades Rubra e Cabocla. Isto pode ser atribuído ao $\mathrm{pH}$ desse genótipo situar-se na faixa de 3,29 que favorece a geleificação do produto (SIQUEMOTO, 1991), ou ainda à presença de pectinas.

Em termos de sabor (Tabela 5) não houve diferença entre os produtos avaliados. Analisandose a média de todos os atributos, o genótipo CMF-017 confirmou a aptidão de variedades mais ácidas para a indústria.

\section{TABELA 5 - AVALIAÇÃO SENSORIAL DE DOCES EM MASSA ELABORADOS COM FRUTOS PROVENIENTES DE DIFERENTES GENÓTIPOS DE ACEROLEIRA}

\begin{tabular}{lccccc}
\hline Genótipos & Aparência & Cor & Aroma & $\begin{array}{c}\text { Ponto de } \\
\text { corte }\end{array}$ & Sabor \\
& & & & & \\
\hline CMF-017 & $6,06 \mathrm{a}$ & $6,18 \mathrm{a}$ & $5,52 \mathrm{a}$ & $6,16 \mathrm{a}$ & $5,54 \mathrm{a}$ \\
RUBRA & $5,04 \mathrm{~b}$ & $5,32 \mathrm{~b}$ & $5,16 \mathrm{a}$ & $5,34 \mathrm{~b}$ & $5,42 \mathrm{a}$ \\
CABOCLA & $5,16 \mathrm{~b}$ & $5,62 \mathrm{ab}$ & $5,20 \mathrm{a}$ & $4,36 \mathrm{c}$ & $5,52 \mathrm{a}$ \\
\hline Média Geral & 5,42 & 5,70 & 5,29 & 5,28 & 5,49 \\
CV $(\%)$ & 28,12 & 22,95 & 27,75 & 29,58 & 31,03 \\
& & & & & \\
\hline
\end{tabular}

$\mathrm{CV}=$ coeficiente de variação.

Médias seguidas pela mesma letra nas colunas não diferem estatisticamente entre si pelo teste de Tukey a $5 \%$ de probabilidade $(\mathrm{P} \leq 0,05)$.

\section{CONCLUSÃO}

Os frutos da variedade Rubra mostraram-se menos ácidos e com maiores teores de sólidos solúveis totais, apresentando melhor desempenho no teste sensorial para o consumo in natura.

Os frutos do genótipo CMF-017 apresentaram maior acidez, característica importante para a indústria. Os doces elaborados com esse genótipo foram considerados superiores no teste sensorial para os atributos de aparência, cor, aroma, ponto de corte e sabor. Desta forma, recomendam-se a variedade Rubra para o consumo in natura e o genótipo CMF-017 para a elaboração de doces.

\section{ABSTRACT}

\section{EVALUATION GENOTYPES AND VARIETIES OF ACEROLA FOR FRESH CONSUMPTION AND MARMALADE ELABORATION}

Acerola fruits differ regarding their composition due to genetic variability, being classified as sweet, semisweet and acid. The objective of this study was the physical-chemical, chemical and sensorial analysis of three in natura and processed acerola (marmalade) genotypes. The fruits evaluated were less acid than those reported in the literature presenting intermediate values of Vitamin C. The Rubra variety had better acceptance for in natura consumption for being less acid and for presenting greater total soluble solids content. The processed fruits (marmalade) differed significantly for the analyzed parameters, according to the genotype used in the elaboration, whereas the CMF-017 genotype offered superior quality to the product.

KEY-WORDS: ACEROLA; Malpighia emarginata; MARMELADE; VITAMIN C.

\section{REFERÊNCIAS}

1 ALMEIDA, M.E.M.; SCHMIDT, F.L.; GASPARINO FILHO, J. Processamento de compotas, doces em massa e geléias: fundamentos básicos. Campinas: ITAL, 1999. 61 p. (Manual técnico, 16). 
2 AOAC. Association of Official Analytical Chemists. Official methods of analysis of AOAC International $15^{\text {th }}$ ed. Arlington, 1990. p.912 - 1010.

3 BRASIL. Instrução normativa n¹, de 7 de janeiro de 2000. Regulamento técnico geral para fixação dos padrões de identidade e qualidade para polpa de fruta. Diário Oficial [da] República Federativa do BRASIL, Brasília, DF, 10 jan. 2000. Seção 1, p. 54-55.

4 BRUNINI, M.A.; MACEDO, N.B.; COELHO, C.V.; SIQUEIRA, G.F. Caracterização física e química de acerolas provenientes de diferentes regiões de cultivo. Revista Brasileira de Fruticultura, Jaboticabal, v.26, n.3, p.486-489, dez. 2004.

5 CARPENTIERI-PÍPOLO, V.; CAVENAGRIPHETE, C.E.; GONZALES, M.G.N.; POPPER, I.O. Novas cultivares de acerola (Malpighia emarginata DC): UEL 3 - Dominga, UEL 4 - Lígia, UEL - Natália. Revista Brasileira de Fruticultura, Jaboticabal, v.4, n.1, p.124-126, abr. 2002.

6 CAVALCANTE, I.H.L.; MARTINS, A.B.G.; ALMEIDA, E.J.; JESUS, N. Caracterização físico-química de dois clones de acerola. In: CONGRESSO BRASILEIRO DE FRUTICULTURA, 18., 2004, Florianópolis. Anais... Florianópolis: SBF, 2004. 1 CD-ROM.

7 CHAVES, M.C.V; GOUVEIA, J.P.G; ALMEIDA, F.A.C.; LEITE, J.C.A.; SILVA, F.L.H. Caracterização físico-química do suco de acerola. Revista de Biologia e Ciências da Terra, Campina Grande, v.4, n.2, 2004. Disponível em: <http:/ /www.uepb.edu.br/eduep/rbct/sumarios/resumos/acerolaresumo.htm>. Acesso em: 27 mar. 2007.

8 FERREIRA, V.L.; ALMEIDA, T.C.A.; PETTINELLI, M.L.C.; SILVA, M.A.A.P.; CHAVES, J.B.P.; BARBOSA, E.M. Análise sensorial de testes discriminativos e afetivos. Campinas: SBCTA, 2000. 127 p. (Manual: Série Qualidade).

9 FRANÇA, V.C. Características físicas, químicas e desenvolvimento de produtos de acerola (Malpighia emarginata D.C.). João Pessoa, 1999. 149 f. Dissertação (Mestrado em Ciência e Tecnologia de Alimentos) Universidade Federal da Paraíba.

10 GOMES, F. P. Curso de estatística experimental. 14. ed. Piracicaba: Nobel, 2000. 477 p.

11 GOMES, J.E.; PERECIN, D.; MARTINS, A.B.G.; FONTES, S. Variações físico-químicas em suco de acerola armazenado. Revista Brasileira de Fruticultura, Jaboticabal, v.22, n.3, p.377-381, 2000.

12 JALALI, V.R.R.; SOUZA, G.M. Produção de geléia de acerola. In: CONGRESSO BRASILEIRO DE FRUTICULTURA, 13., Salvador, 1994. Resumos... Salvador: SBF,1994. v .1, p.103.

13 LASKOWSKI, L.E.; BAUTISTA, D. Evaluacion de caracteristicas vegetativas, productivas y de calidad de la fruta de plantas de semeruco cultivadas en zonas aridas. Agronomia Tropical, Maracay, v.48, n.3, p.239-249, 1998.

14 LEES, R. Food analysis: analytical and quality control methods for the food manufacturer and buyer. London: Leonard Hill, 1975. 245 p.

15 MANICA, I. Processamento e aproveitamento da acerola. In: MANICA, I.; ICUMA, I.M.; FIORAVANÇO, J.C.; PAIVA, J.R.; PAIVA, M.C.; JUNQUEIRA, N.T.V. Acerola: tecnologia de produção, pós-colheita, congelamento, exportação, mercados. Porto Alegre: Cinco Continentes, 2003. p.337-374.

16 MANICA, I.; ICUMA, I.M.; JUNQUEIRA, N.T.V.; JUNQUEIRA, T.V. Pomar doméstico-caseiro-familiar, frutas de primeira qualidade na família $\mathbf{3 6 5}$ dias do ano. Porto Alegre: Cinco Continentes, 2007. 114 p.

17 MINOLTA. Chroma meter CR-300: instruction manual. Osaka, 1991. 90 p.

18 MUSSER, R.S.; LEMOS, M.A.; LIMA, V.L.A.G.; MÉLO, E.A.; LEDERMAN, E.E.; SANTOS, V.F. Características físicoquímicas de acerola do Banco Ativo de Germoplasma em Pernambuco. Ciênc. Tecnol. Aliment., Campinas, v.24, n. 4, p.556-561, 2004

19 OLIVEIRA, J.R.P.; SOARES FILHO, W.S.; KOBAYASHI, A.K.; RITZINGER, R. Aspectos botânicos. In: RITZINGER, R.; KOBAYASHI, A.K.; OLIVEIRA, J.R.P. A cultura da aceroleira. Cruz das Almas: Embrapa Mandioca e Fruticultura, 2003. $198 \mathrm{p}$.

20 RITZINGER, R.; SOARES FILHO, W.S.; OLIVEIRA, J.R.P. Variedades e melhoramento. In: RITZINGER, R.; KOBAYASHI, A.K.; OLIVEIRA, J.R.P. A cultura da aceroleira. Cruz das Almas: Embrapa Mandioca e Fruticultura, 2003. 198 p.

21 SEMENSATO, L.R. Caracterização físico-química de frutos de genótipos de acerola (Malpighia emarginata sp.) cultivados em Anápolis-Go, processamento e estabilidade de seus produtos. Goiânia, 1997. $74 \mathrm{f}$. Dissertação (Mestrado em Agronomia) - Universidade Federal de Goiás.

22 SIGUEMOTO, A.T. Propriedades da pectina. In: SIMPÓSIO SOBRE HIDROCOLÓIDES, Campinas, 1991. Anais... Campinas: ITAL, 1993. 109 p.

23 STABLE MICRO SYSTEMS. User guide: texture expert for Windows. Surrey, 1997. 155 p. 